\title{
Regional variations in seasonality of births in Nigeria, 1990-2007: A trigonometric regression model approach
}

\author{
Leonard K. Cheserem ${ }^{1}$, Joshua O. Akinyemi ${ }^{2}$, Olusola Ayeni ${ }^{2}$ \\ Population Studies and Research Institute, University of Nairobi ${ }^{1}$ \\ Department of Epidemiology and Medical Statistics, College of Medicine, University of \\ lbadan $^{2}$ \\ lenaches@gmail.com
}

\begin{abstract}
Background: Seasonality of births in Nigeria has been previously addressed in a small number of studies. This study was designed to explore and describe the regional variations in the seasonality of births in Nigeria.

Data Source and Methods: A total of 82,827 births history data collected in the Nigerian Demographic Survey 2008 were analyzed. It covered periods between January 1990 and December 2007. Seasonal variation by month of birth was explored with the aid of correlogram. A classical time series trigonometric regression model was fitted to describe the pattern of seasonality.

Findings: The reported monthly distribution for number of births showed a significant seasonal pattern with a peak in May and corresponding minima in November. Birth patterns differ across the regions, but in every region, births are concentrated in the first half of the year.

Conclusion: Though, birth seasonality is more pronounced in the northern part of the country, there has been significant shift in the magnitude of variation in the 18 year period of study.
\end{abstract}

Keywords: Seasonality of Births, Time series, Correlogram, Magnitude of variation, Nigeria.

\section{Introduction}

Seasonality of births remains a global phenomenon both in the natural world and human societies. Human species are considered fertile throughout the year which brings about existence of different demographic trends across regions. The absence of seasonal rhythm is considered abnormal (Arcury et.al, 1990; Roenneberg and Aschof, 1990; Gunn, 1992). Birth rhythmic patterns vary greatly from country to country. Many factors have been postulated to account for these seasonal variations but still researchers have remained mystified as to what causes this intriguing seasonal birth patterns (Cummings, 2002).

Explaining causes and mechanisms behind the observed seasonal patterns of human births are still not fully understood due to varying number of births by season. The frequency of intercourse for example in Malaysia among different religious/ethnic groups reflected the impact of Ramadan and Chinese New Year with different patterns of birth seasonality (Meade and Earickson, 2000; Rajan and James, 2000). The September peak in births may be associated with a "Christmas effect", although this may not necessarily be of a strictly Christian religious nature given that the peak in births in that month is also a characteristic of non-Christian countries (Cesario, 2002). Polašek et.al (2005) and James (1990) pointed out to the increased number of conceptions during (religious) holidays, such as Easter and, most notably, Christmas, as the most important explanation for birth seasonality. Some authors call attention to the importance of leisure time, which increases during holidays or vacations. Thus in Gambia for instance, conception rates reduced during the season when workloads are maximal, women are subject to nutritional stress, have less time to breastfeed, and suckling by hungry or sick infants is reduced (Lunn et.al. 1981). In Kenya, the factors responsible for birth seasonality in Turkana pastoralists were clearly related to rainfall and the same could be observed in that of agro-pastoralist Fulani in Mali (Leslie et.al. 1989) but required further analysis of rates of ovulation and intra-uterine mortality (Leslie et.al. 1993).

Marriages have been indicated to exhibit a cyclical fluctuation which is also understood to be correlated to the cyclical pattern of births (Kevan, 1979; Lam and Miron, 1991; Underwood, 1991). This of course 
must operate through the frequency of sexual intercourse and conception probabilities. Marriages could also have effect on birth seasonality (Trovato and Odynak, 1993) while marital status has been explained to exhibit a pattern. Cogwill (1966) indicated that illegitimacy of births increases the amplitude of seasonality, i.e. non-marital births follow a more pronounced seasonal pattern than marital births. Dividing births into marital and non-marital births could have some more patterns explained.

One of the most important findings in America and European patterns of birth seasonality is that there is trough in April followed by an increase in the number of births in the periods after April until fall for the American pattern. The European pattern is characterized by a peak early in the year (usually the spring) with decrease in the number of births for the rest of the year but with an exception in September when there is peak in births again (Seiver 1985). Extreme heat may have been an effect both for male reproductive capability and female fecundability. But according to Becker (1991), there is reduced spermatogenesis during peak temperatures of the year.

Various studies from Australia (Mathers and Harris, 1982), Czech Republic (Babak and Gjonca, 200I) and Haryana in India (Anand et.al, 2000) have all agreed that there are other factors such as climate cycles, heat, temperature and photoperiod which cause variability in pattern of seasonality. According to Lam and Miron (199I, 1996), extreme temperatures especially summer heat suppresses fecundity. This can be partly attributed to the September peaks in births for some Northern hemisphere countries. Closely related to heat and temperature is the photoperiod which has been investigated to be a possible external cause on reproduction (Roennenberg and Aschof, 1990). Claims has been made by Barber (2002) supporting the hypothesis that human reproduction can be indeed be suppressed by the short photoperiods and low temperatures.

Although seasonality of births in man for developed countries and Indian countries have been documented extensively in literature, seasonality of births in Nigeria has been addressed in a small number of studies (Ogum et.al., 1979; Ayeni 1986; Shittu et.al., 2008). The seasonal patterns have altered due to social change and also probably because of climatic change. There has been concern about others factors like global warming, the greenhouse effect, the hole in the ozone layer, atmospheric pollution, and other environmental changes.

This study provides contemporary documentation on birth seasonality in Nigeria and its regions. The 3167 existence of peaks and valleys in the number of births (in Nigeria) leads to the need of associating factors that apparently affect or explain seasonality by regions. This was important as Nigeria is one of Africa's countries faced with greatest challenges of managing high population growth. Understanding seasonality of birth occurrence in the country especially across the various regions of Nigeria is vital for policy makers in strategizing towards managing the country's explosive population growth especially those concerning reproductive health issues i.e. to control fertility.

Nigerian Demographic and Health Survey (NDHS) in Nigeria started in 1990 and the study is based on the fourth (NDHS 2008). Data from survey are always prone to be inconsistent and incomplete. Many probes are being done with questionnaire but still DHS uses a multiple way to impute and deal with incomplete data collected. A woman's recollection of the date of birth may be more accurate for births that occur within five or ten years of the interview date. It is also possible that mother's are less likely to include children that have died (especially as infants) in their survey responses. This is problematic because in many countries some birth months are associated with excess infant mortality (Kynast-Wolf et al., 2005).

The availability of data from the NDHS studies has provided an excellent opportunity to examine larger sets of data spread over the entire country, the ability to compare regions living in the same country and, hence subject to the same natural, but different socio-cultural seasonality. Therefore we examined seasonal monthly variation in number of births in Nigeria for over 18 years from 1990 to 2007.

\section{Materials and Methods \\ Data Source}

The data used is from NDHS 2008. The data for the number of births by month, which covers the period January 1990 to December 2007, was extracted for 18 years (1990-2007) by months. The monthly values were then adjusted for the varying number of days in the month essentially standardizing to 30-day month. A total of 82,827 births, 40,553 Females and 42,274 male number of births recorded which comprised of 14,823 (North Central), 19,22 I (North East), 23,356 (North West), 7,090 (South East), 9,I48 (South West) and 9, 189 (South South).

\section{Statistical analysis}

A Cosinor model (Nelson et.al 1979) was used to model birth seasonality. The Cosinor model requires repeated observations on any characteristic of an individual to follow/obey a trigonometric (sinusoidal) regression function. It uses sine and cosine wave to http://aps.journals.ac.za 
approximate the observed pattern. This model was used to summarize the parameter estimation of the peak in births which consisted of monthly births made on study years.

A time series for the data was plotted for the preliminary examinations of the linear trend. Autocorrelation was calculated and used to examine the existence of serial correlation in the series by checking if the values lie between $\pm 2 / \sqrt{N}$, where $n_{i}$ corresponds to the number of events (e.g. Births) in month $\mathrm{i}$ and $\sum_{i}^{k(=12)} \boldsymbol{n}_{i}=N$

As a means of investigating whether the series contains seasonal fluctuations with a sinusoidal pattern, a correlogram was plotted then trigonometric regression was employed to fit the trigonometric curve in order to assess the seasonal variation.

Cosinor analysis involved representation of data span by the best-fitting cosine function of the form: $Y_{t}=M+A \cos (\omega t+\varphi)+\varepsilon_{t}$

$Y_{t}$ is the number of births occurring in the t-th ordinal month starting from January (i.e. $t=I$ corresponds to January 1990), $M$ is the mean number of births per month between the years, $A$ gives the amplitude of the function, $\omega$ is the angular frequency (period) of the curve, $\varphi$ is the acrophase (peak) of the curve, the time when the peak occurs, measured in $0^{\circ}$. $0-30^{\circ}$ therefore represents the month of January, $30-60^{\circ}$ February, etc. and $\varepsilon_{\mathrm{t}}$ is the error term assumed to be Gaussian (Mean zero and Variance $\sigma^{2}$ )

The equation was fitted to the data by conventional least squares regression analysis. The model was reparameterized to a linear multiple regression of the form:

$Y_{t}=M+B_{1} X_{1 t}+B_{2} X_{2 t}+\varepsilon_{t}$

Where;

$$
\begin{array}{ll}
\mathrm{X}_{1 \mathrm{t}}=\cos (\omega t) & \mathrm{X}_{2 \mathrm{t}}=\sin (\omega t) \\
\mathrm{B}_{1}=\mathrm{A} \cos (\varphi) & \mathrm{B}_{2}=-\mathrm{A} \sin (\varphi) \\
\omega=\frac{2 \pi}{T}, \text { the angular frequency was set on }
\end{array}
$$

our knowledge of the pattern; this was often based on 12 months

M was estimated by $\bar{Y}=\frac{1}{N} \sum_{t=1}^{N} Y_{t}$

Therefore A was estimated by

http://aps.journals.ac.za
$A=\sqrt{\left(B_{1}^{2}+B_{2}^{2}\right)}, \mathrm{B}_{1}$ and $\mathrm{B}_{2}$ was obtained in the usual way from normal equations

The estimates of $\varphi$ was given by;

$\varphi=\tan ^{-1}\left(-\frac{B_{2}}{B_{1}}\right)$ if $\mathrm{B}_{1}>0$

But if

$$
\begin{array}{ll}
\mathrm{B}_{1}=0, \mathrm{~B}_{2}>0 & \varphi=-\frac{\pi}{2} \\
\mathrm{~B}_{1}=0, \mathrm{~B}_{2}<0 & \varphi=-\frac{\pi}{2} \\
\mathrm{~B}_{1}<0, \mathrm{~B}_{2}<0 & \varphi=\pi+\tan ^{-1}\left(-\frac{B_{2}}{B_{1}}\right) \\
\mathrm{B}_{1}<0, \mathrm{~B}_{2}>0 & \varphi=\tan ^{-1}\left(-\frac{B_{2}}{B_{1}}\right)-\pi
\end{array}
$$

(Bloomfield, 1976)

The extent of the seasonal variation above the mean level was measured by $\frac{A}{M}$ while the time of the highest variation was obtained by solving the equation $\cos \pi=0$, the optimum time was reached when $\pi=\omega t+\varphi$, where $\omega=\frac{2 \pi}{T}$. This was converted to months and days.

Hence,

$$
t_{\max }=\frac{\pi-\varphi}{\omega}=T\left(0.5-\frac{\varphi}{2 \pi}\right)
$$

We performed this time series approach using Generalized Linear Model regressions from the Gaussian families. Gaussian models were used for fitting 'count' outcome variables when the sample was large and the means of the variables were large. The above analysis was done for the series as a whole and separately for the six regions in attempt to examine whether they vary in the time of the maxima over the years. Once the time series analyses were complete, the characteristics of the pattern from the total birth series were described, as well as those of the series between 1990 and 2007. This verified the existence of seasonality and established the similarities and differences in the evolution by decades. The findings were then contrasted with other international series.

Results were considered to be of statistical significance if the relevant $\mathrm{P}$-value was $<0.05$. Statistical analyses were performed using SPSS (version 20) and STATA (version II). 
Results

Table I shows the monthly percentage distribution of the adjusted birth history each year for the entire study period. Preliminary investigation of the data shows that the highest number of births occurs in the months of April and June in 16 out of 18 years.

Table I: Percentage distribution of births by month in Nigeria, 1990-2007

\begin{tabular}{|c|c|c|c|c|c|c|c|c|c|c|c|c|c|c|}
\hline Year & Jan & Feb & Mar & Apr & May & Jun & Jul & Aug & Sep & Oct & Nov & Dec & Total & $\mathbf{N}$ \\
\hline 1990 & 10.5 & 11.0 & 10.6 & 11.8 & 9.5 & 10.9 & 8.5 & 6.9 & 5.5 & 5.5 & 4.4 & 4.8 & 100.0 & 3154 \\
\hline |99| & 9.3 & 9.6 & 10.4 & 10.2 & 9.5 & 11.6 & 8.0 & 7.8 & 7.4 & 6.0 & 5.0 & 5.2 & 100.0 & 2475 \\
\hline 1992 & 10.1 & 10.1 & 10.9 & 11.1 & 9.7 & 9.7 & 8.7 & 7.5 & 6.2 & 6.6 & 4.0 & 5.5 & 100.0 & 3089 \\
\hline 1993 & 9.8 & 9.4 & 8.8 & 12.5 & 9.9 & 10.8 & 8.7 & 7.7 & 7.1 & 5.0 & 5.3 & 4.9 & 100.0 & 3578 \\
\hline 1994 & 11.1 & 9.4 & 10.3 & 8.5 & 9.7 & 12.2 & 8.4 & 8.2 & 6.8 & 5.6 & 4.2 & 5.7 & 100.0 & 3643 \\
\hline 1995 & 9.3 & 9.2 & 9.6 & 10.0 & 9.3 & 11.5 & 8.7 & 8.5 & 7.8 & 6.1 & 4.7 & 5.3 & 100.0 & 3726 \\
\hline 1996 & 10.3 & 10.2 & 10.5 & 11.8 & 9.4 & 10.0 & 9.5 & 8.3 & 6.0 & 5.1 & 4.3 & 4.5 & 100.0 & 4321 \\
\hline 1997 & 9.6 & 8.9 & 9.6 & 10.3 & 9.2 & 10.7 & 8.6 & 7.2 & 6.9 & 6.7 & 6.0 & 6.4 & 100.0 & 3475 \\
\hline 1998 & 10.4 & 10.2 & 11.2 & 10.9 & 9.8 & 11.8 & 9.1 & 6.6 & 5.9 & 5.4 & 4.2 & 4.3 & 100.0 & 5435 \\
\hline 1999 & 8.8 & 9.2 & 10.1 & 10.3 & 9.4 & 10.0 & 8.7 & 8.0 & 7.2 & 6.9 & 5.3 & 6.1 & 100.0 & 4290 \\
\hline 2000 & 12.5 & 9.6 & 10.7 & 10.6 & 8.8 & 10.2 & 8.4 & 7.5 & 6.3 & 5.4 & 4.2 & 5.8 & 100.0 & 6189 \\
\hline 2001 & 10.3 & 9.2 & 9.7 & 10.7 & 10.0 & 10.9 & 9.1 & 7.9 & 7.2 & 5.4 & 4.6 & 5.1 & 100.0 & 5068 \\
\hline 2002 & 11.3 & 8.8 & 10.8 & 12.3 & 10.7 & 10.2 & 8.6 & 6.7 & 6.2 & 5.3 & 4.2 & 4.9 & 100.0 & 6251 \\
\hline 2003 & 9.5 & 8.6 & 9.4 & 11.7 & 9.9 & 10.9 & 8.2 & 7.4 & 8.0 & 6.2 & 4.7 & 5.4 & 100.0 & 4933 \\
\hline 2004 & 9.5 & 8.2 & 9.9 & 8.9 & 10.1 & 11.5 & 9.6 & 8.5 & 6.7 & 5.9 & 5.3 & 5.9 & 100.0 & 5701 \\
\hline 2005 & 8.4 & 8.3 & 10.1 & 10.7 & 8.9 & 12.1 & 9.8 & 8.8 & 6.9 & 5.8 & 4.8 & 5.6 & 100.0 & 5827 \\
\hline 2006 & 7.7 & 8.4 & 8.9 & 9.6 & 9.1 & 10.4 & 9.6 & 9.0 & 7.8 & 6.3 & 6.1 & 7.2 & 100.0 & 5640 \\
\hline 2007 & 7.1 & 7.0 & 8.2 & 8.0 & 8.7 & 9.4 & 9.2 & 9.1 & 9.1 & 8.9 & 6.9 & 8.3 & 100.0 & 6032 \\
\hline $\begin{array}{l}1990- \\
2007\end{array}$ & 9.7 & 9.1 & 10.0 & 10.5 & 9.5 & 10.8 & 8.9 & 7.9 & 7.0 & 6.0 & 4.9 & 5.7 & 100.0 & 82827 \\
\hline
\end{tabular}

Figure I below shows high percentage of births between April and June with a steady reduction in percentage of births with corresponding minima in November and figure 2 depicts trend of seasonal variations of births in Nigeria 1990-2007, the series plot of monthly births for the 18 years of study period. The number of births reported shows a rising trend with high birth numbers in the years 1999 and 2001. There was no significant linear trend which indicated differential reporting rates over the consecutive years.

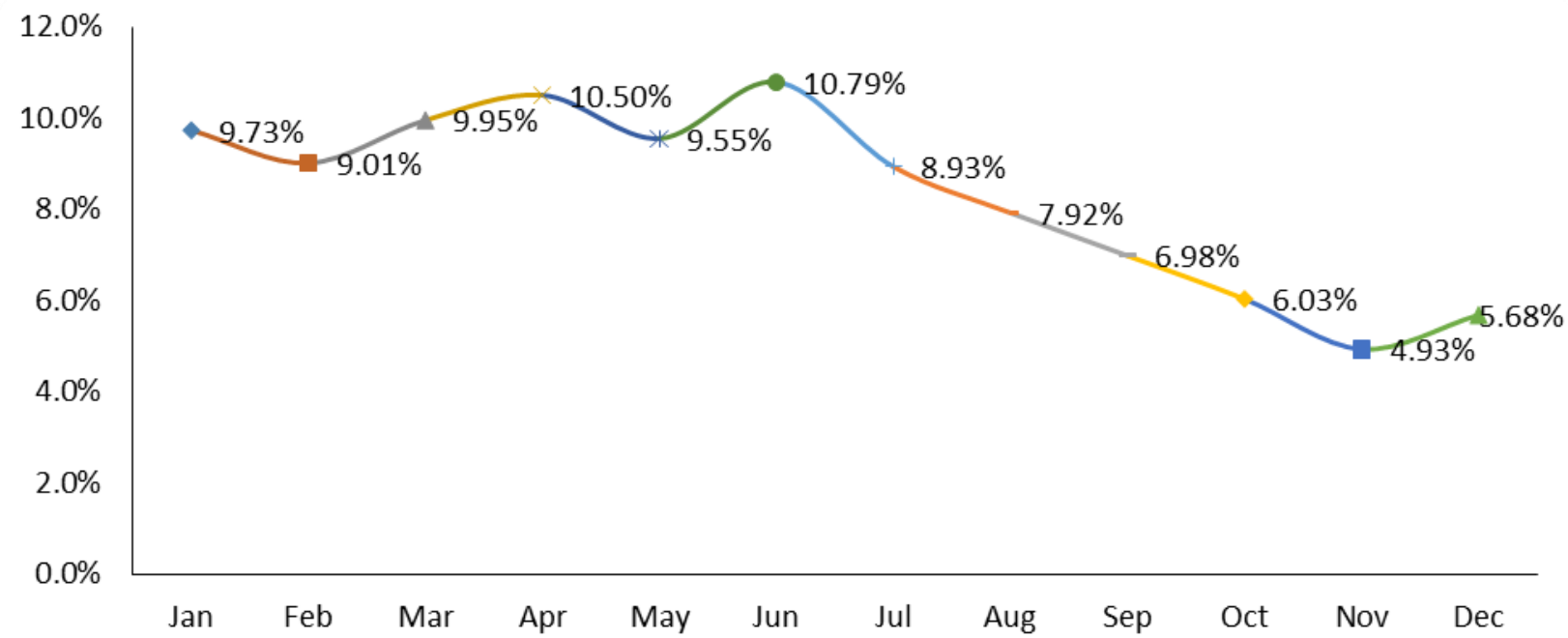


Figure I: Percentage distribution of number of births

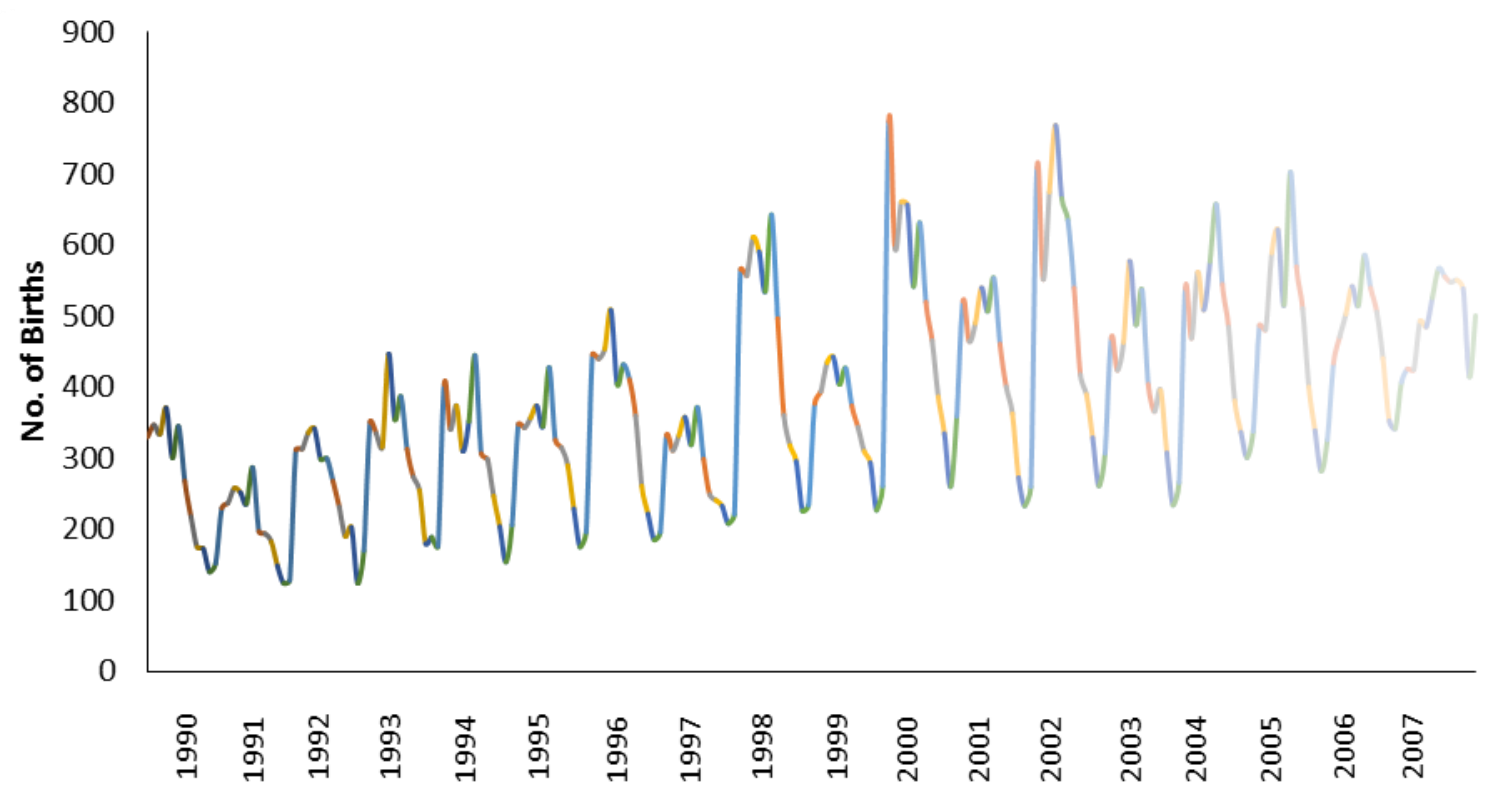

Figure 2: Adjusted monthly births, 1990-2007

Table 2 below shows values of autocorrelations up to lag 40 with values not in the range $\pm 2 / \sqrt{N}$ which needed adjustments for serial correlations. The births correlogram in figure 3 displays a sinusoidal pattern indicating existence of seasonal variations, for the raw data figure 3(a) as well as for the seasonally adjusted data in figure $3(b)$ which indicates short term correlation in that some month births are higher than average for that month which tend to be followed by months with lower births.

Table 2: Autocorrelations of total birth at lag $\mathrm{k}$ up to $\mathrm{k}=\mathbf{4 0}$

\begin{tabular}{|l|l|l|l|}
\hline $\mathbf{k}$ & Autocorrelations & $\mathbf{k}$ & Autocorrelations \\
\hline $\mathbf{2}$ & 0.788798 & 21 & 0.258375 \\
3 & 0.62778 & 22 & 0.424045 \\
4 & 0.440288 & 23 & 0.579806 \\
5 & 0.226297 & 24 & 0.746993 \\
6 & 0.104001 & 25 & 0.605808 \\
7 & 0.004467 & 26 & 0.49636 \\
8 & 0.032443 & 27 & 0.334159 \\
9 & 0.10118 & 28 & 0.142588 \\
10 & 0.271472 & 29 & 0.023515 \\
11 & 0.411237 & 30 & -0.07459 \\
12 & 0.557538 & 31 & -0.07263 \\
13 & 0.694206 & 32 & -0.02102 \\
14 & 0.565913 & 33 & 0.126042 \\
15 & 0.429844 & 34 & 0.25401 \\
16 & 0.284796 & 35 & 0.393776 \\
17 & 0.09731 & 36 & 0.523227 \\
18 & 0.008675 & 37 & 0.418223 \\
19 & -0.06053 & 38 & 0.326206 \\
\hline
\end{tabular}




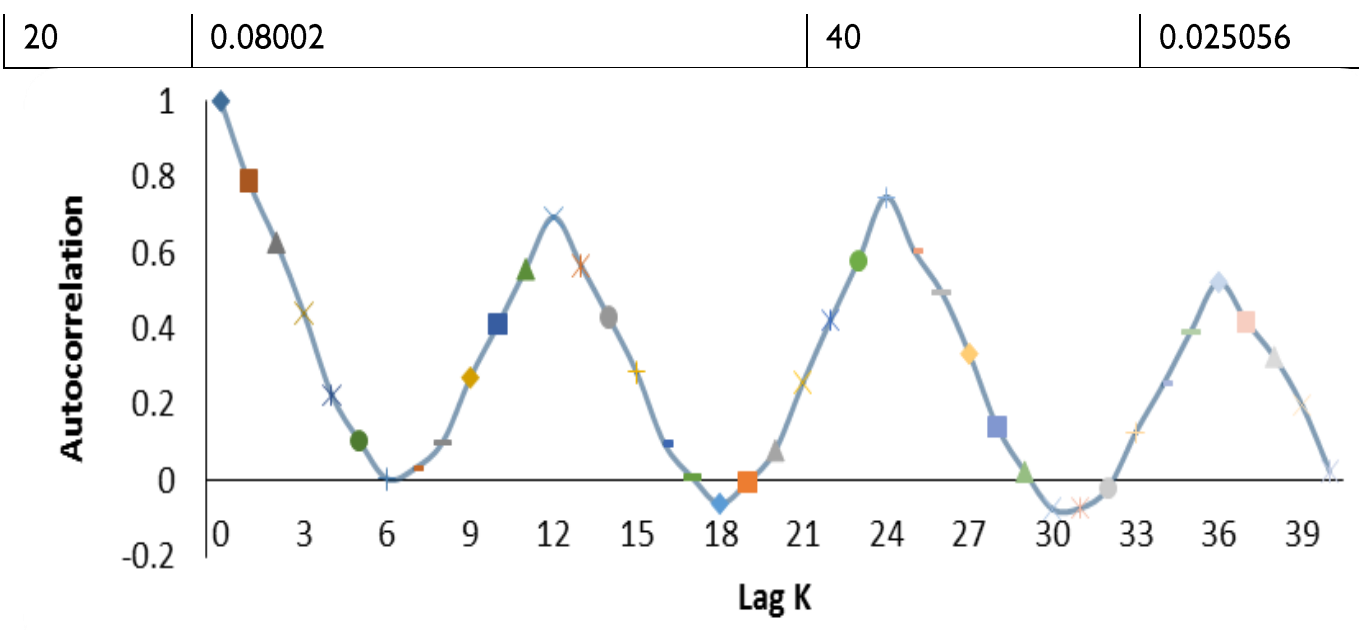

Figure 3(a). Birth correlogram for raw data

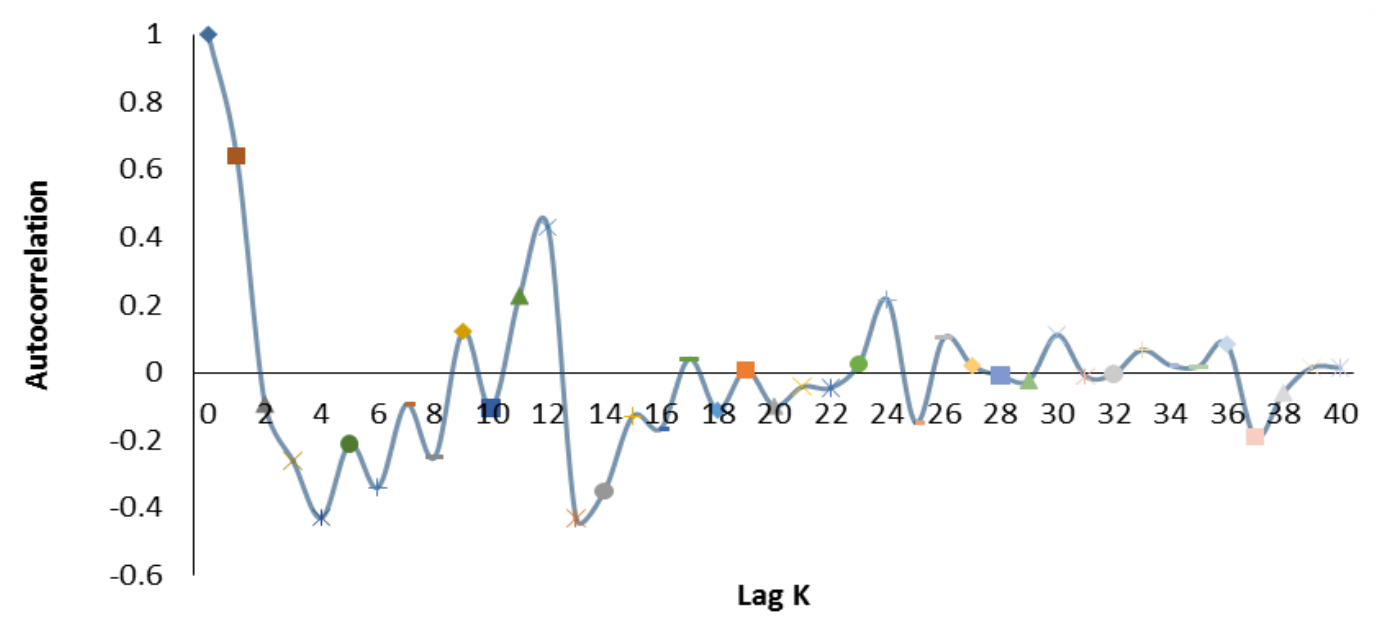

Figure 3(b): Birth correlogram for seasonally adjusted data

Figure 4 displays the six regions trend plots. North while the rest of the three regions had similar trend West had a higher series fluctuation in number of in number of births which was almost flattened. The births followed by North East then North Central north had larger surfing than the south.

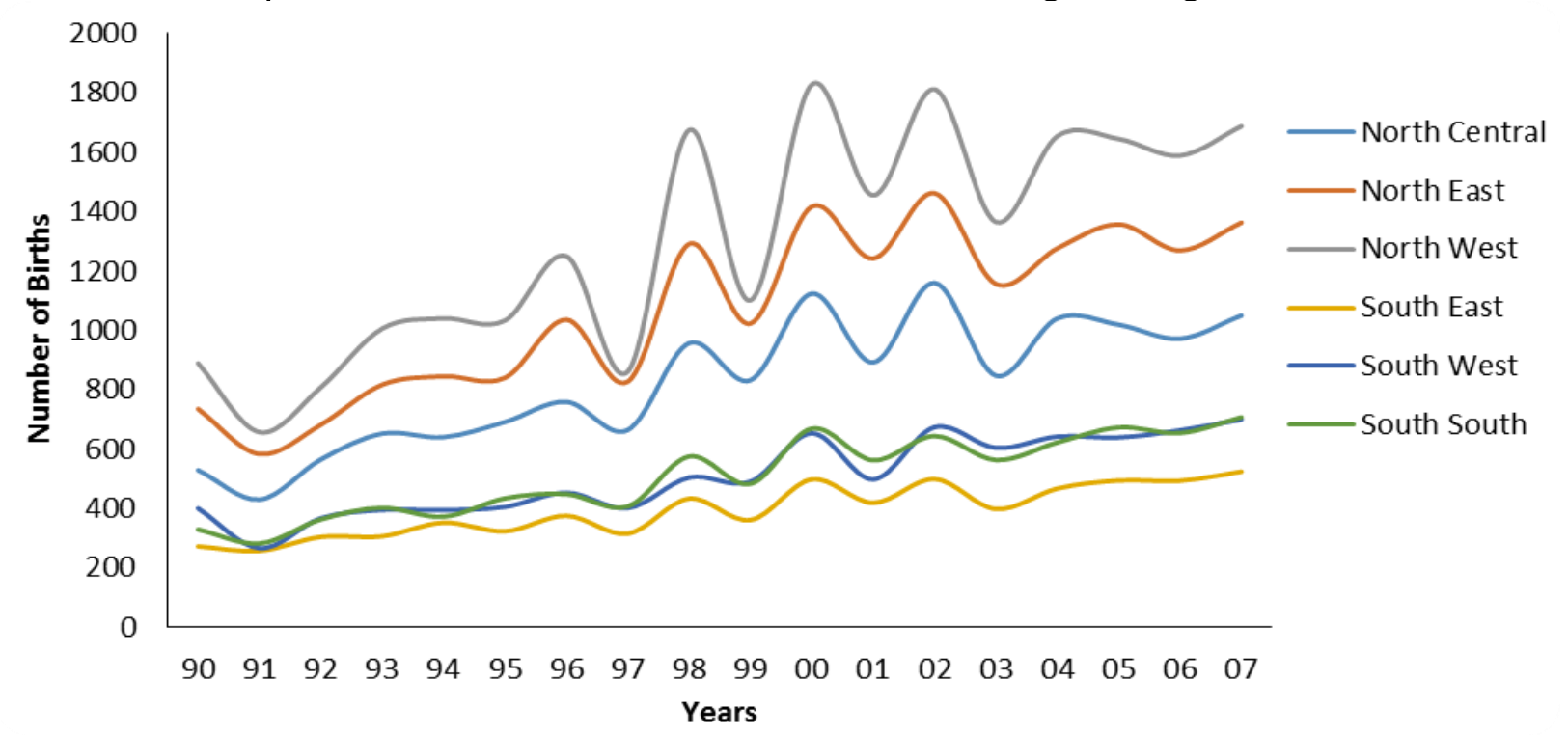


Figure 4: Regional trends of births

Table 3 shows results of trigonometric regression analysis for the periods as a whole and for each subsequent six segments after adjusting for trend. All the models fitted for a simple trigonometric regression had a good fit $(P<0.05)$. There was a steady increase in mean number of births from 242 (1990-1992) to 486 (2005-2007). The extent of seasonal variations for the entire 18 year period varied about $30 \%$ above and below the annual mean due to significant heterogeneity between regions (as shown in Figure 4) with an estimated peak occurring in the month of May. Therefore the analysis was done for Northern and Southern Nigeria separately.

Table 3: Results of Trigonometric regression of Nigerian births (NDHS 2008)

\begin{tabular}{|c|c|c|c|c|c|c|c|}
\hline Period & $F$ & $\mathbf{P}$ & $M$ & A & $\frac{A}{M}$ & $\begin{array}{c}\text { Acrophase } \\
\varphi\left({ }^{\circ}\right)\end{array}$ & Estimated Peak \\
\hline $1990-2007$ & 49.08 & 0.0001 & 383.46 & 111.76 & 0.29 & -136.3 & May 16 \\
\hline 1990-1992 & 34.04 & 0.0001 & 242.17 & 84.86 & 0.35 & -146.5 & May 27 \\
\hline |993-|995 & 35.06 & 0.0001 & 304.08 & 92.83 & 0.31 & -134.0 & May I4 \\
\hline |996-| 998 & 17.13 & 0.0001 & 367.53 & 130.34 & 0.35 & -142.9 & May 23 \\
\hline$|999-200|$ & 15.46 & 0.0001 & 431.86 & 129.24 & 0.30 & -144.82 & May 25 \\
\hline 2002-2004 & 29.25 & 0.0001 & 469.03 & $|53.9|$ & 0.33 & -137.1 & May 17 \\
\hline $2005-2007$ & 22.63 & 0.0001 & 486.08 & 95.63 & 0.20 & -106.6 & April I7 \\
\hline
\end{tabular}

Table 4 shows results obtained from trigonometric regression analysis which indicated that the models for the periods were significant $(P<0.05)$. The magnitude of variation was $31 \%$ high and $16 \%$ low above and below the annual mean in urban areas compared to a magnitude of variation was $31 \%$ high and $5 \%$ low in rural areas. A similar trend was observed for number of births with peak in the month of May but later shifted to June.

Table 4: Results of trigonometric regression analysis of urban and Rural Nigeria, 1990-2007

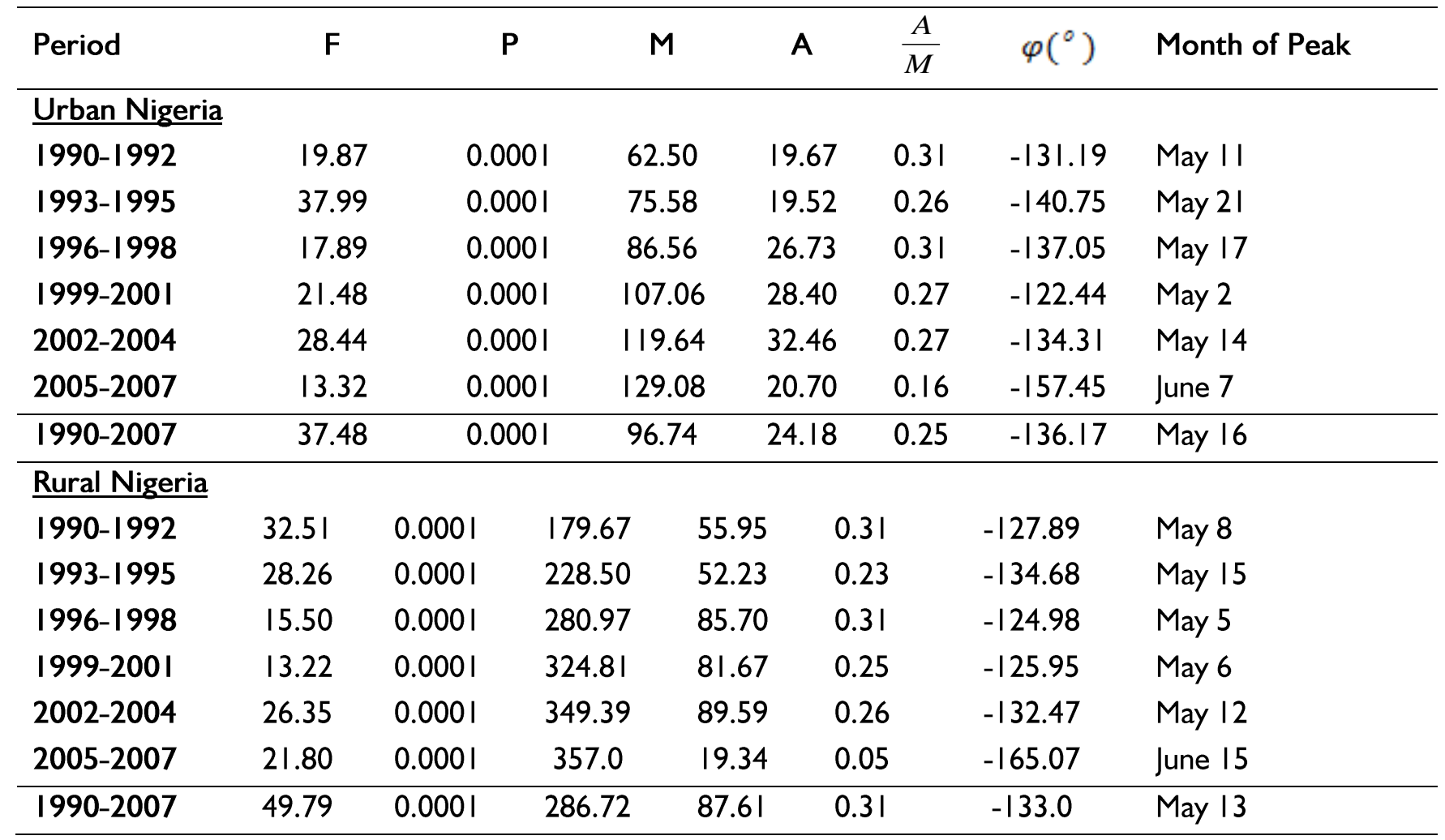

Table 5 below shows the results of trigonometric regression analysis for the year's studies after http://aps.journals.ac.za adjustment for trend. In all cases the simple trigonometric model was a good fit as shown by $F$ 
and $P$ values in columns 2 and 3 respectively. For the entire period the monthly number of births varied between $38 \%$ and $24 \%$ above and below the annual mean and the births were peaked at month of May.
Although May remained to be the month of peak occurrence for most years, but for the last three the maxima occurred a month later, in June.

Table 5: Results of Trigonometric regression analysis of Northern Nigeria, 1990-2007

\begin{tabular}{lccccccl}
\hline Year & F & P & M & A & $\frac{A}{M}$ & $\varphi^{o}$ & Estimated Peak \\
\hline $1990-1992$ & 30.27 & 0.0001 & 163.28 & 56.52 & 0.36 & -123.25 & May 3 \\
$1993-1995$ & 21.43 & 0.0001 & 210.11 & 62.4 & 0.31 & -138.46 & May 18 \\
$1996-1998$ & 15.60 & 0.0001 & 258.89 & 98.21 & 0.38 & -126.34 & May 6 \\
$1999-2001$ & 14.37 & 0.0001 & 303.17 & 96.47 & 0.32 & -124.68 & May 5 \\
$2002-2004$ & 25.96 & 0.0001 & 327.00 & 123.0 & 0.37 & -133.46 & May 13 \\
$2005-2007$ & 24.59 & 0.0001 & 332.0 & 80.0 & 0.24 & -164.0 & June 14 \\
\hline $1990-2007$ & 50.82 & 0.0001 & 265.74 & 85.56 & 0.32 & -134.55 & May 15 \\
\hline
\end{tabular}

The results of trigonometric regression analysis for South Nigeria for years of study after adjusting for trend is shown in table 6. The trigonometric models were significant $(P<0.05)$ as can be shown by $F$ and $P$ in columns 2 and 3 respectively. For the first 13 years, the extent of variation was between $29 \%$ and
$22 \%$ but for the last five years it was between $17 \%$ and $7.6 \%$. Similarly for the whole series (1990-2007) trigonometric model the magnitude of variation was $21 \%$. The estimated peak occurred on the month of May for the first fifteen years but occurred a month after and before during the last three years.

Table 6: Results of Trigonometric regression analysis of Southern Nigeria, 1990-2007

\begin{tabular}{|c|c|c|c|c|c|c|c|}
\hline Year & $F$ & $\mathbf{P}$ & $M$ & $A$ & $\frac{A}{M}$ & $\varphi^{\circ}$ & Estimated Peak \\
\hline $1990-1992$ & 28.46 & 0.0001 & 78.89 & 23.24 & 0.29 & -124.08 & May 4 \\
\hline 1993-1995 & 51.77 & 0.0001 & 93.97 & 25.0 & 0.26 & -130.0 & May 10 \\
\hline 1996-1998 & 16.83 & 0.0001 & 108.64 & 26.43 & 0.24 & -129.82 & May 10 \\
\hline |999-200| & $|4.4|$ & 0.0001 & 128.69 & 28.0 & 0.22 & -126.78 & May 7 \\
\hline $2002-2004$ & 17.20 & 0.0001 & 142.03 & 25.6 & 0.17 & $-|30.2|$ & May 10 \\
\hline $2005-2007$ & 3.93 & 0.029 & 154.08 & 11.7 & 0.076 & -159.82 & June 10 \\
\hline $1990-2007$ & 32.64 & 0.0001 & 117.72 & 24.84 & 0.21 & $-|30.7|$ & May II \\
\hline
\end{tabular}

In table 7 of results of trigonometric regression analysis urban areas in Northern and Southern Nigeria, all the trigonometric models were of good fit as shown by values of $F$ and $P$ in the table. There was an increase in mean number of births as can be depicted by column 4. The extent of seasonal variation was high as $38 \%$ (1990-1992) and low as $18 \%(2005-2007)$ in the north compared to 22\%(1996-1998) high and I3\% (2005-2007) low for southern region above and below the mean with an estimated peak in May for the first fifteen years but the peak occurred a month later, in June.

Table 7: Results of trigonometric regression analysis of urban areas in the North and South Nigeria, 1990-2007

\begin{tabular}{llllllll}
\hline Series & $\mathrm{F}$ & $\mathrm{P}$ & $\mathrm{M}$ & $\mathrm{A}$ & $\frac{A}{M}$ & $\varphi^{\circ}$ & Estimated peak \\
\hline
\end{tabular}

\section{Northern Nigeria}




\begin{tabular}{|c|c|c|c|c|c|c|c|}
\hline 1990-2007 & 45.04 & 0.0001 & 54.59 & 15.56 & 0.28 & $-|33.5|$ & May 14 \\
\hline |990-|992 & 20.41 & 0.0001 & 35.44 & 13.6 & 0.38 & -128.02 & May 8 \\
\hline |993-|995 & 17.59 & 0.0001 & 43.72 & 12.54 & 0.29 & -142.02 & May 22 \\
\hline |996-|998 & 18.86 & 0.0001 & 49.31 & 17.69 & 0.36 & $-|32.3|$ & May 12 \\
\hline | 999-200| & 13.13 & 0.0001 & 61.33 & 17.0 & 0.28 & -118.06 & April 28 \\
\hline 2002-2004 & 23.05 & 0.0001 & 67.86 & 21.9 & 0.32 & -134.15 & May 14 \\
\hline 2005-2007 & 10.05 & 0.0001 & 69.89 & 12.53 & 0.18 & $-|52.8|$ & June 3 \\
\hline \multicolumn{8}{|c|}{ Southern Nigeria } \\
\hline | 990-2007 & 17.85 & 0.0001 & 42.24 & 7.21 & 0.17 & $-14 \mid .6$ & May 22 \\
\hline |990-1992 & 6.31 & 0.005 & 27.06 & 5.0 & 0.185 & -139.02 & May 19 \\
\hline |993-|995 & 13.60 & 0.0001 & 31.86 & 6.40 & 0.20 & -138.45 & May 18 \\
\hline |996-| 998 & 6.71 & 0.004 & 37.25 & 8.06 & 0.22 & -147.25 & May 27 \\
\hline | 999-200| & 14.89 & 0.0001 & 45.72 & 10.0 & 0.22 & -129.92 & May 10 \\
\hline 2002-2004 & 9.74 & 0.0001 & 51.78 & 9.80 & 0.19 & -134.67 & May I5 \\
\hline 2005-2007 & 6.20 & 0.005 & 59.18 & 7.50 & 0.13 & -165.85 & June 17 \\
\hline
\end{tabular}

The results of trigonometric regression analysis of rural setting in the Northern and Southern Nigeria are displayed in table 8. All trigonometric models were of a good fit as can be indicated by $F$ and $P$ values in columns 2 and 3 respectively. There was an increase in number of births (shown by values of $M$ ).
The magnitude ranged about $39 \%$ and $27 \%$ in the north which was higher than $20 \%$ and $5 \%$ of the south respectively. The estimated peak occurred in May for the first fifteen years then shifted a month after, in June

Table 8: Results of trigonometric regression analysis of rural areas in the North and South Nigeria, 1990-2007

\begin{tabular}{|c|c|c|c|c|c|c|c|}
\hline Series & $F$ & $\mathbf{P}$ & $M$ & A & $\frac{A}{M}$ & $\varphi^{\circ}$ & Estimated peak \\
\hline \multicolumn{8}{|c|}{ Northern Nigeria } \\
\hline $1990-2007$ & 49.15 & 0.0001 & 211.15 & 69.3 & 0.33 & -134.8 & May 15 \\
\hline 1990-1992 & 26.11 & 0.0001 & 127.83 & 44.42 & 0.35 & -121.8 & May 2 \\
\hline |993-1995 & 19.20 & 0.0001 & 166.39 & 52.40 & 0.31 & -137.62 & May 18 \\
\hline |996-|1998 & 13.83 & 0.0001 & 209.58 & 81.34 & 0.39 & -125.02 & May 5 \\
\hline |999-200| & 13.35 & 0.0001 & 241.83 & 80.21 & 0.33 & -126.15 & May 6 \\
\hline 2002-2004 & 24.28 & 0.0001 & 259.14 & 101.86 & 0.39 & $-|33.3|$ & May 13 \\
\hline 2005-2007 & 26.12 & 0.0001 & 262.11 & 69.86 & 0.27 & -166.09 & June 16 \\
\hline \multicolumn{8}{|c|}{ Southern Nigeria } \\
\hline 1990-2007 & 37.32 & 0.0001 & 75.57 & 17.2 & 0.22 & -125.8 & May 6 \\
\hline |990-1992 & 32.22 & 0.0001 & 51.83 & 10.16 & 0.19 & -120.0 & April 30 \\
\hline 1993-1995 & 33.05 & 0.0001 & 62.11 & 12.60 & 0.20 & -127.22 & May 7 \\
\hline |996-|998 & 17.21 & 0.0001 & 71.39 & 11.65 & 0.16 & -122.94 & May 3 \\
\hline |999-200| & 9.91 & 0.0001 & 82.97 & 11.49 & 0.14 & -125.13 & May 5 \\
\hline 2002-2004 & 13.98 & 0.0001 & 90.25 & 11.5 & 0.14 & -127.88 & May 8 \\
\hline 2005-2007 & 1.25 & 0.301 & 94.89 & 5.14 & 0.054 & $-|5| .0$ & June I \\
\hline
\end{tabular}

From figure 5 below, there exists a higher fluctuation in number of births for the consecutive months for the northern region especially between the months of April and July unlike the southern region. Similar pattern can be seen in figure 6 of rural number of births for the two regions. 


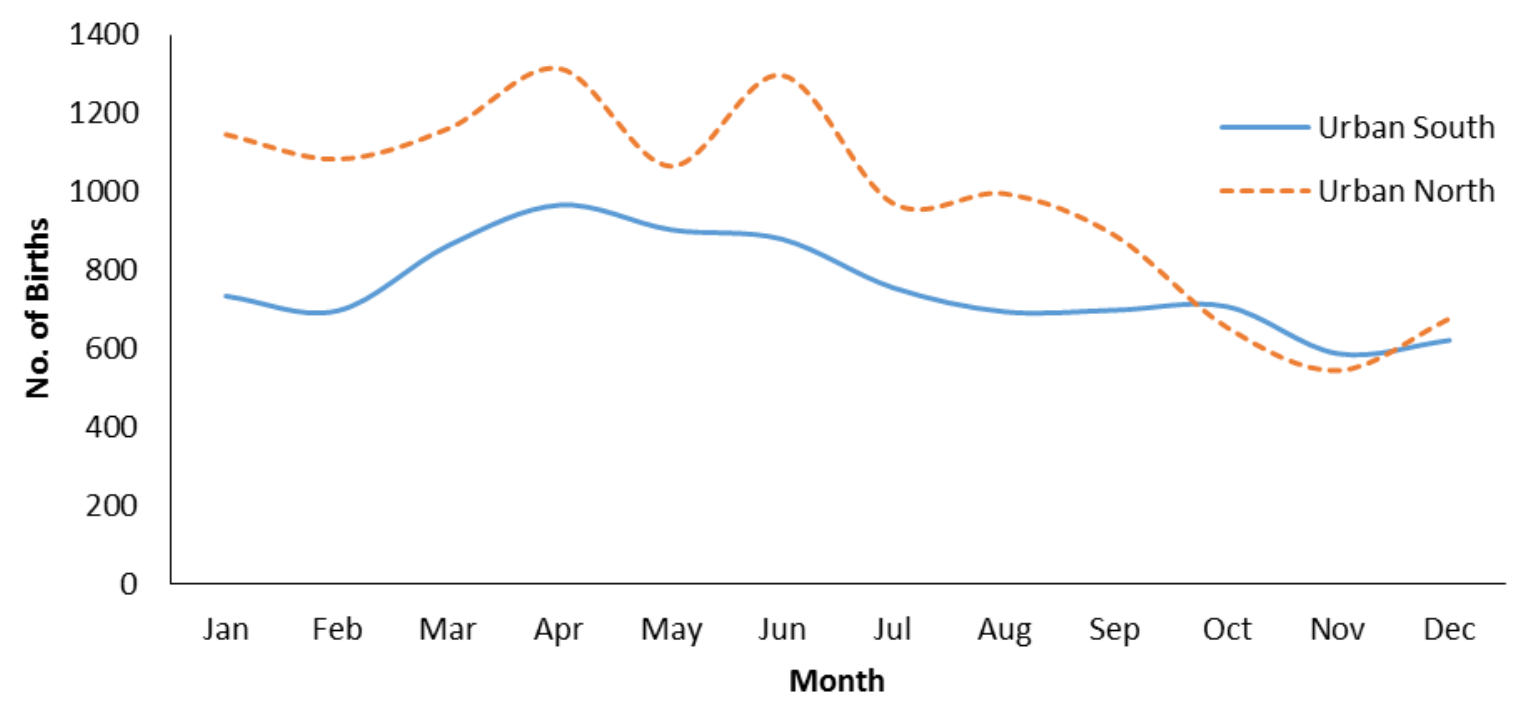

Figure 5: Plot of urban number of births for Southern and Northern Nigeria

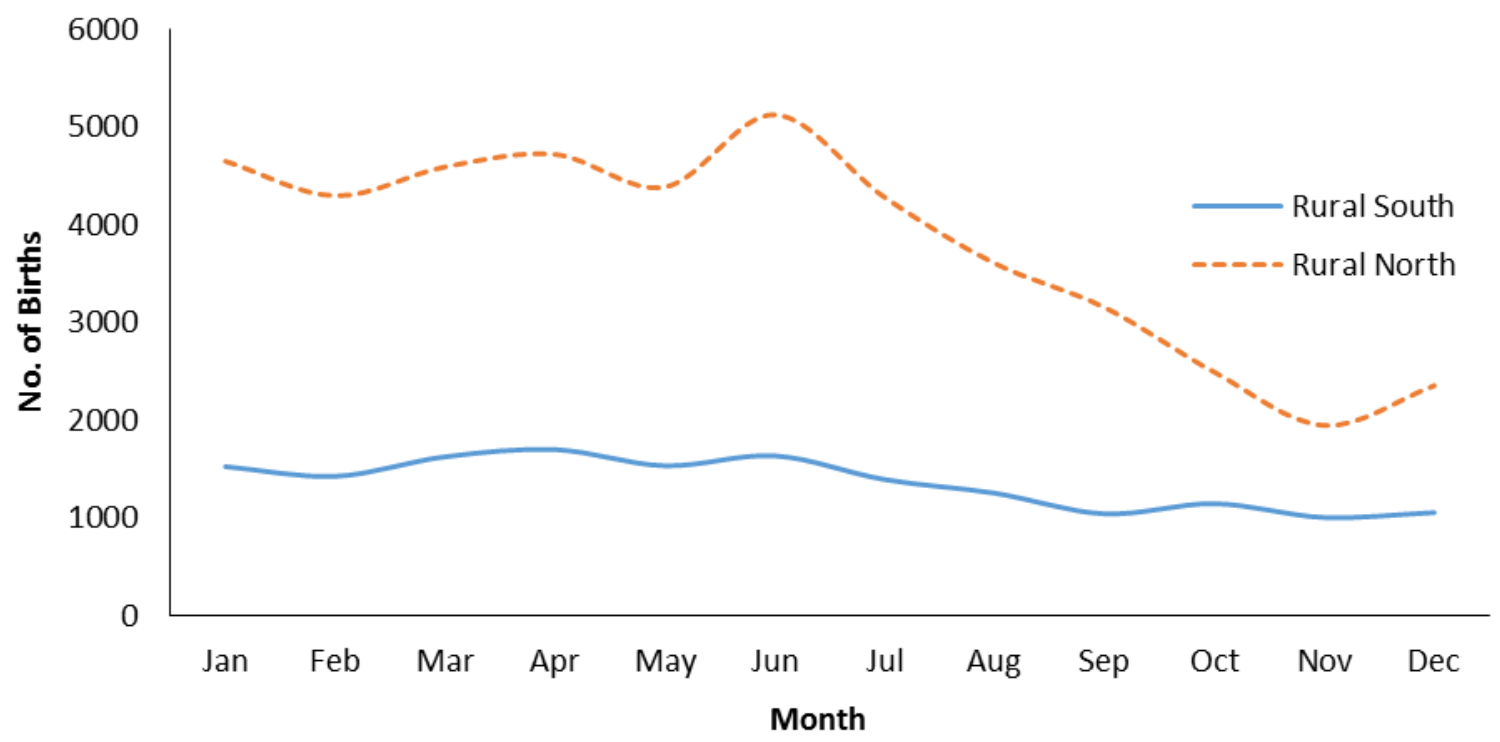

Figure 6: Rural number of births of Southern and Northern Nigeria

\section{Discussions}

The present study describes seasonal pattern of births in Nigerian as a whole and its regions. The accuracy of reported data has already been emphasized. There appears to be some serious data quality issues making comparison difficult. It is unusual for members of a predominantly non-literate, isolated population to remember birth dates in such detail (although precise data are confined to live births). Reproductive histories, obtained from faceto-face interviews with individual women who collaborated during several surveys, yielded remarkably consistent data for the number but timing of births might have likely due to recall error 3175 especially ten or over five years before the present study which meant that period between the last

survey (NDHS 2003) and the present survey (NDHS 2008) used in the study gave a good estimate of seasonality differences observed which were pronounced due to pattern of births across regions.

Our findings show that in Nigeria during the 18 years studied, seasonal variation in the birth rate showed the peak relatively stayed constant at May for first fifteen years but later shifted to June in the last three years. There is agreement with previous reports from Nigeria that found the maxima in number of births to occur between April and July (Ogum et.al, 1979; Ayeni, 1986; Shittu et.al, 2008) http://aps.journals.ac.za 
using less or more sophisticated methods of analysis. The same was depicted by reports from Czech Republic, Britain 1960's, Canada, Australia and France but on the other hand, they differ from AugustSeptember peak experienced in Netherlands and USA. Indian sub-continent showed a peak occurring during the months of August and September and the trough during March and April. Explanations of the birth rhythm found in different parts of the world can be divided into the American and the European patterns. The classic European pattern usually with the main peak in spring (summer conceptions) and a smaller one in the autumn (winter conceptions) but for the American is enigmatic. In the past 70 to 80 years, the slope of the arrival rhythm was reversed from the classic European pattern into a smaller early spring peak and a larger plateau in the autumn. This was a change which was experienced to the north, Canada or to the south, Mexican where the European pattern persisted. The Nigerian seasonality pattern does not follow any of the above patterns. Patterns of seasonality (Lam and Miron, 1994) vary with latitude, in very hot climatic conditions i.e. West Africa and Indian sub-continents conceptions are mainly in the cooler winter while temperate zones are in summer.

We find that birth patterns differ across the regions, but in every region, births are concentrated in the first half of the year. The magnitude of birth seasonality for Nigeria was about $20 \%$ above and below the annual mean. Variation was highest in the urban part of the country (16\%) when compared with the rural $(5 \%)$ part. There has been no study conducted for the whole country. From our findings, it was noted that the Southern part of the country was significantly different from the Northern part (figure 4) and the northern part had higher swings. From the NDHS report 2008, fertility varies dramatically by zone. Women in the South West zone have an average of 4.5 children compared with 7.3 children per women in the North West zone therefore extent of variations was high in the Northern part (Table 4) of the country as compared to the Southern region (Table 5).

The present study agrees with reports by Shittu et.al (2008), Ogum et.al (1979) and Ayeni (1986) on the May peak and it was concordant with what was found by Shittu et.al (2008) of urban areas having significantly higher magnitude of variation than rural areas. However the magnitude of $18 \%$ and $7 \%$ for urban and rural areas respectively reported earlier for South Western Nigeria was higher compared with the one found for urban (13\%) and rural (5\%) areas for southern Nigeria in the present study. This result was a contrast of the northern situation where urban areas had lower magnitude of seasonal variation http://aps.journals.ac.za
(I8\%) compared to rural areas (27\%). This is due to the pastoral and agro-pastoral communities present in the region and according to NDHS report 2008 three-quarters of women in the North West zone have no formal education. This gives rise to teenage childbearing to be high in the region. Seasonality of births have been reported for different parts of the world including Australia (Matters and Harris, 1983), Canada (Halli, 1989), US (Rosenberg, 1966; Erhardat et.al, 197I), Pakistan (Stoeckel and Choudhury, 1972) and India (Anand et.al, 2000). The extent of variation $(20 \%)$ indicated was not high as Indian subcontinent (34\%) and East Pakistan (40\%) in the study compared to literature. Lower values depicted for Australia (5\%), 7\% for Accra and Kumasi and around 10-15\% for Japan (Matsuda and Kahyo, 1994) has been reported. A study from Bangladesh (198I) which is similar to India in its geo-cultural characteristics also reported high amplitude of variation (40\%).

Nigeria is a mixed of urban and rural way of life, although more people are still in rural areas (Figure 6) especially in the northern part it can be suggested that change in way of life (urban life style) due to increased use of birth control methods found in NDHS report 2008 (13\% in 2003 to $15 \%$ in 2008) especially among the southern region. Northerners are mostly Muslims and according to their religious believe family planning is not an ideal practice instead they practice more a polygamous type of marriage. This changes are ascribed to agree with Canada (Halli, 1989), industrialization and Americanization in Japan (Matsuda, 1994) and Religious practice (Rajan and James, 2000). The availability of contraceptives may affect the seasonality of births as couples decide on the time of conception. Contraceptive prevalence rate (CPR) in the study area was 15 percent among currently married women using any method of contraception. There was an increase in CPR from 13 percent in the NDHS 2003. Among women using contraception, twice as many use a modern method of contraception (10\%) when compared with use of traditional methods (5\%). With respect to specific modern methods, injectables (3\%), male condoms, and the pill ( $2 \%$ each) are the most widely used methods.

There are other fascinating aspects of birth seasonality. The male/female birth ratio changes by season and area to area (Ayeni, 1975; Azeez, 2007). In the same community singleton births have a different seasonality from multiple births. Enabudoso et.al (20I I) found the months of April, May, and October had delivery rates that were significantly higher than the monthly average delivery rate, while the converse was true for July, August, and December at the $99 \%$ confidence interval which 
indicated existence of significant monthly variation in delivery rates. Although meteorologic, biologic, and socio-cultural factors, among others, continue to be discussed as possible determinants of the seasonal distributions of births.

\section{Conclusion}

The study has shown both significant seasonal variation in births, and considerable changes in the form of that variation over the 18 years studied. The number of births in this environment peak in the month of May with corresponding minima in the month of November. This was shown to remain constant throughout the series except for the last which suggests that there might be a possibility of the peak to shift to June after some time since seasonality continues to evolve in the number of births and with microclimate differences in adjacent regional locations can also have a major effect. Environmental influences may have contributed to the changes; recently that there has been much debate about the role of pollution. The social changes of the past 18 years have been profound and it could be that the mechanism is both social and environmental. Assuming a 40-week gestation it can be inferred that most of the conceptions occur in late August and early September since this are the coolest months of the year after a rainy reason which usually lasts from April to October. June is the wettest month of the year therefore months after are conducive for increased cohabitation and excess mating. Availability of leisure time due to slackness in agricultural work may result in increased sexual activity and this coincide with months of August and September which have been known to be the period with lightest work and this relative form of idleness can be ascribed to more mating (Ogum et.al, 1979).

There is need for further studies on the effect of genetic, hormonal, environmental and social factors on seasonality of births in the Nigerian population. It may be possible to a have a bio-social model to suggest the above suppositions to help quantify seasonality in future. Also more studies are needed to understand the pattern of seasonality in Northern Nigeria which seemed to have high variation.

\section{Acknowledgements}

I wish to acknowledge my classmates and colleagues at University of Ibadan, Nigeria for their support. They brought to this difficult and daunting task considerable energy and enthusiasm-essential qualities for any effort of this scope. Also I am indebted to all my Lecturers and Non-academic staff in the Department of Epidemiology, Medical Statistics and Environmental Health. Finally, I appreciate the World Health Organization (WHO) for the 3177 scholarship to study M.Sc Biostatistics at University of Ibadan without which this research could not been done.

\section{References}

Anand, K., Kumar, G., Kant, S., \& Kapoor, S. K. (2000). Seasonality of births and possible factors influencing it in a rural area of Haryana, India.Indian pediatrics, 37(3), 306-31 I.

Arcury, T.A, Williams BJ, Kryscio, R. J. (1990). Birth seasonality in a rural US county, 191 I-1979. Am J Hum Biol; 2:675-89.

Ayeni, O. (1986). Seasonal variation of births in rural southwestern Nigeria. International journal of epidemiology, I5(I), 91-94.

Azeez, M. A., Akinboro, A., \& Bakare, A. A. (2007). Human sex ratio at birth in South West Nigeria. Indian journal of human genetics, I3(2), 59.

Barber, N. (2002). On the relationship between fertility and geographic latitude: A cross-national study. Cross-Cultural Research, 36(I), 3-I5.

Bloomfield, P. (2004). Fourier analysis of time series: an introduction. John Wiley \& Sons.

Bobak, M., \& Gjonca, A. (200I). The seasonality of live birth is strongly influenced by sociodemographic factors. Human reproduction, 16(7), I5I2-I5I7.

Cesario, S.K. (2002). The "Christmas Effect" and Other Biometeorologic Influences on Childbearing and the Health of Women, Journal of Obstetric, Gynecologic, \& Neonatal Nursing; 3I(5), 526-35

Cowgill, U. M. (1966). Season of birth in man. Contemporary situation with special reference to Europe and the southern hemisphere. Ecology, 6|4-623.

Cummings, David R. "The seasonality of human births, melatonin and cloud cover." Biological rhythm research 33, no. 5 (2002): 52I-559.

Enabudoso, E. J., Okpighe, A. C., Gharoro, E. P., \& Okpere, E. E. (20II). Delivery rate in Benin City, Nigeria: Are there seasonal variations?. Nigerian journal of clinical practice, |4(2), |29-131.

Erhardt, C. L., Nelson, F. G., \& Pakter, J. (197I). Seasonal patterns of conception in New York City. American journal of public health, 6I(II), 2246-2258.

Gunn, P.A. (1992). Seasonality of births in nineteenth-century urban Tasmania. Hum Biol;64:5I-65

Halli, S. S. (1989). The seasonality of births in Canada. Journal of biosocial science, 2I(3), 32I-327.

James,W.H. (1990). Seasonal variation in human births, Journal of Biosocial Science; 22( I): I I3-9.

Kevan, S. M. (1979). Season of life-season of death. Social Science \& Medicine. Part D: Medical Geography, I3(4), 227-232.

http://aps.journals.ac.za 
Kynast-Wolf, G., Hammer, G. P., Müller, O., Kouyaté, B., \& Becher, H. (2006). Season of death and birth predict patterns of mortality in Burkina Faso. International journal of epidemiology, 35(2), 427-435.

Lam, D. A., \& Miron, J. A. (1996). The effects of temperature on human fertility. Demography, 33(3), 29I-305.

Lam, D. and Miron, J. A. (| 99|). Seasonality of births in human populations. Social Biology; 38: 5I-78.

Leslie P. W and Fry P. H. (1989). Extreme seasonality of births among nomadic Turkana pastoralists', American Journal of Physical Anthropology; 79: 103-II5.

Leslie P. W, Campbell K. L and Little M. A. (1993). Pregnancy loss in nomadic and settled women in Turkana, Kenya: A prospective study. Human Biology; 65 (2): 237-254.

Lunn, P.G., Watkinson M, Prentice A. M, Morrell P, Austin S and Whitehead R. G. (I98I). Maternal nutrition and lactational amenorrhea, Lancet; I: |428-| 429.

Mathers, C. D., \& Harris, R. S. (1983). Seasonal distribution of births in Australia. International Journal of Epidemiology, I2(3), 326-331.

Matsuda, S., \& Kahyo, H. (1994). Geographical differences and time trends in the seasonality of birth in Japan. International journal of epidemiology, 23(I), 107-II8.

Meade, M. and Earickson, R. (2000). Medical Geography. New York

Nelson, W., Tong, Y. L., Lee, J. K., \& Halberg, F. (1979). Methods for cosinor-rhythmometry. Chronobiologia, 6(4), 305.

National Population Commission (NPC) [Nigeria] \& ICF Macro. (2009). Nigeria Demographic and
Health Survey 2008. Abuja, Nigeria: National Population Commission and ICF Macro

Ogum, G. E. O., \& Okorafor, A. E. (1979). Seasonality of births in south-eastern Nigeria. Journal of biosocial science, II(02), 209-2I 7.

Polašek, O., I. Kolčić, A. Vorko-Jović, J. Kern and I. Rudan. (2005). Seasonality of Births in Croatia, Collegium Antropologicum; 29(I): 249-55.

Rajan, S. I. and James, K. S. (2000). The interdependence of vital events: twentieth century Indian Kerala. Journal of Interdisciplinary History; 3I: $2|-4|$.

Roenneberg, T., \& Aschof, J. (1990). Annual rhythm of human reproduction: I. Biology, sociology, or both?. Journal of Biological Rhythms, 5(3), 195216.

Rosenberg, H. M. (1966). Seasonal variation of births, United States, 1933-63. Vital and health statistics. Series 21, Data from the National Vital Statistics System, (9), I.

Seiver, D. A. (1985). Trend and variation in the seasonality of U.S. fertility. Demography; 22: 89100.

Shittu O.I, Oyeniyi, T.A and Olatayo, T.O. (2008). The seasonality of births in urban south western Nigeria. Advances and applications in statistics; I0(2): 219-235

Stoeckel, J., \& Choudhury, A. K. M. (1972). Seasonal variation in births in rural East Pakistan. Journal of biosocial science, 4(0I), 107-II6.

Trovato, F. and Odynak, D. (1993). The seasonality of births in Canada and the provinces, 1881-1989: theory and analysis, Canadian Studies in Population; 20(I): I-4I.

Underwood, J. H. (199|). Seasonally of vital events in a pacific island population. Social biology, 38(I-2), II3-126 